\title{
XRF Standardless Comparison of Mining Head and Tail Grades to Screen and Display Ore Processing Recoveries
}

\author{
Nicholas E. Pingitore Jr${ }^{1 *}$, Juan W. Clague ${ }^{2}$, Daniel Gorski ${ }^{3}$ \\ ${ }^{1}$ Department of Geological Sciences, The University of Texas at El Paso, El Paso, Texas, USA \\ ${ }^{2}$ Environmental Engineering \& Public Health, LLC, El Paso, Texas, USA \\ ${ }^{3}$ Texas Mineral Resources Corporation, Sierra Blanca, Texas, USA \\ Email: *npingitore@utep.edu
}

How to cite this paper: Pingitore Jr, N.E., Clague, J.W. and Gorski, D. (2016) XRF Standardless Comparison of Mining Head and Tail Grades to Screen and Display Ore Processing Recoveries. American Journal o1 Analytical Chemistry, 7, 785-796. http://dx.doi.org/10.4236/ajac.2016.711070

Received: September 10, 2016

Accepted: November 1, 2016

Published: November 4, 2016

Copyright $\odot 2016$ by authors and Scientific Research Publishing Inc. This work is licensed under the Creative Commons Attribution International License (CC BY 4.0).

http://creativecommons.org/licenses/by/4.0/ (c) (i) Open Access

\begin{abstract}
Separation of target elements or minerals from their host rock or ore is essential to successful mining operation. The inevitable loss of a portion of the desired material that accompanies each step in the extraction process must be documented to develop the operational protocol. Superposition of the characteristic X-ray fluorescence spectra of head (crushed rock ore particles, pre-processing) and tail (post-processing particles) samples provides a direct visual comparison of relative peak sizes, and thereby the relative concentrations, of elements of interest. If the head and tail peaks are identical, none of the element was recovered in the extraction process. At the other extreme if the tail peak "flat lines", i.e., there is no peak, there was $100 \%$ recovery of that element. Standardless visual comparison is valid if the same mass of identical starting material is incorporated into the head and tail sample analysis pucks, and XRF analytical conditions are identical. The considerable time and expense of acquiring and calibrating the standards associated with XRF analysis of 75 or more elements are avoided, a significant advantage during initial broad screening of an experimental extraction procedure. Full quantitation by XRF or an alternate technique can proceed at a later project stage, if desired. The approach retains and presents all features of the original data, thus eliminating questions about data quality, standards and their calibration, and data manipulation in processing from raw counts to concentrations in printout tables. This form of display is ideal for both the mining professional and such less technical groups as corporate staff, investors, regulators, and the public. Examples presented herein are for heap leaching; the protocol can be applied as well to any of the other traditional ore processing and beneficiation procedures, e.g., gravity concentration, magnetic and electrical separation, froth flotation, and ore sorting.
\end{abstract}




\section{Keywords}

XRF (X-Ray Fluorescence), Ore Processing, Heap Leach, Standardless Analysis, Round Top Mountain, Rare Earth Elements

\section{Introduction}

The mining process involves a number of steps that route the raw material of economic interest from the ground to a concentrated or purified target element (e.g., gold or silver metal) or compound (e.g., $\mathrm{Li}_{2} \mathrm{CO}_{3}$ ). Extraction from the earth's surface or subsurface is only the first step in mining, and often not the most financially demanding one. Economic success commonly hinges on the beneficiation and purification of the ore into the desired end materials. A loss of the target element or compound accompanies each step of the process; documenting and tracking that loss is essential to process optimization and financial success [1]-[7].

For low-grade, high-volume open pit mining operations, e.g., copper porphyry or Carlin-type gold deposits, heap leaching preferentially releases the target material from a stack of finely crushed base rock via irrigation with an appropriate chemical solution [8]-[13]. To design such a process, extensive initial bench-scale testing is required to determine, from an economic standpoint, the ideal combination of grain size, solvent, solvent-rock volume ratio, reaction time, evaporation potential, etc. Bench scale testing is typically followed by pilot plant field testing to determine whether the bench process can be scaled up successfully. Bench and field scale testing both involve considerable chemical analytical work to determine the achieved recoveries.

For many mining operations, typical laboratory analytical instrumentation falls into two categories: dissolution techniques in which the samples are dissolved prior to analysis, such as ICP-OES, ICP-MS, and AA, and solid techniques, such as XRF, XRD, optical and electron microscopy, and electron probe microanalysis. Here we discuss a method for rapid, standardless analysis of bulk samples by XRF.

Traditional XRF analysis of minerals and ores associated with mining was typically performed in the laboratory setting, either on-site or at an outside contract assay company. This approach has been augmented by increasing use of relatively inexpensive hand-held, cordless XRF instruments for both mineral exploration and mining on-site analyses. Both tube and radioactive isotope sealed sources are available to supply the $\mathrm{X}$-ray beam. There thus has been considerable research on applications of the portable XRF, or pXRF, in mineral processing [14] [15] [16] [17] [18]. In general, although the pXRF units are inferior in detection limits and accuracy compared to their laboratory counterparts, they nonetheless have proved adequate to many mining-related tasks. Advances also have come about in the application of X-ray tomography to the minerals and mining commercial sectors. This new technique has allowed 3-dimensional imaging of ore materials and of the effects of metallurgical processing of those ore materials [19] [20] [21]. 
Our primary task was to evaluate the feasibility of heap leaching the massive surface-exposed yttrium and heavy rare earth (YHREE) deposit at Round Top Mountain, near the town of Sierra Blanca, Texas, USA. The mountain is some $375 \mathrm{~m}$ in height and almost $2 \mathrm{~km}$ in diameter, and nearly all, extending into the subsurface, comprises a peraluminous rhyolite laccolith intrusion (a fine-grained igneous rock in the granite family, with a mushroom shape, and molar proportion $\mathrm{Al}_{2} \mathrm{O}_{3}>\mathrm{Na}_{2} \mathrm{O}+\mathrm{K}_{2} \mathrm{O}+\mathrm{CaO}$ ). Virtually all of the mountain is mineralized, with elevated levels of not only YHREEs, but also the light rare earth elements (LREES), Li, Be, Ga, Cs, Rb, Sn, Nb, Ta, U, and Th [22] [23] [24].

Texas Mineral Resources Corporation (TMRC) completed an extensive drilling and sampling program that documented rare earth element (REE) levels of approximately $500 \mathrm{ppm}$, of which an unusual $72 \%$ is YHREEs [25]. Mineralization grade proved remarkably consistent in the examined portions of the estimated 1.6-billion-tonne deposit [24] [25]. The extremely fine grain size of the major host mineral for the HREEs, yttrofluorite (a YHREE-substituted variety of the mineral of fluorite), rendered separation of the yttrofluorite grains from the gangue by traditional froth flotation feasible but cost-prohibitive due to the very fine grinding that would be required to mechanically free the yttrofluorite grains [26] [27] [28].

Because yttrofluorite is soluble in a number of dilute mineral acids, we set about testing the recovery of YHREEs and other potential byproduct elements in a series of bench-scale leaching experiments that varied particle size, acid type, acid strength, solution-rock ratio, temperature, agitation, and leach time [26] [29]. To speed the analytical process, we decided to use ED-XRF (energy dispersive XRF) to examine the full range of elements accessible on our instrument, $\mathrm{Na}$ to $\mathrm{U}$. This would provide the most comprehensive view of how the leach process was progressing. A significant advantage of the XRF over our laboratory's high resolution magnetic sector ICP-MS was no requirement to dissolve each sample, a tedious and time-consuming multi-step procedure in a silicate rock such as our rhyolite. Dissolution of such resistate minerals as the zircon $\left(\mathrm{ZrSiO}_{4}\right)$ found in the rhyolite presented an additional challenge. The preparation of standards, the production of calibration curves, and the continuous recalibrations for nearly 80 ICP-MS standards presented yet another stumbling block.

We developed a simple scheme for rapid, standardless ED-XRF analysis and graphical display of our head (pre-leach crushed rock particles) and tail (post-leach particles) samples. Our procedure is simply to superimpose the characteristic X-ray spectra of the head and tail samples and visually compare the peak sizes. Where there is no recovery of an element into solution, the two peaks are identical. Where there is $100 \%$ recovery, the tail peak "flat lines", i.e., there is no peak. More precise numerical determination of \% recovery is easily achieved via the instrument software (e.g., peak areas), if desired. Because the same mass of material is incorporated into the head and tail pucks, and analytical conditions are identical, such direct comparison proves valid. 


\section{Experimental}

\subsection{Rhyolite Material}

Material for experimental leaching was taken from a well mixed $250 \mathrm{~kg}$ sample composited from a characteristic subset of the more than 100 reverse circulation drill holes in the rhyolite at Round Top Mountain, Texas. This material was crushed and subdivided via a riffle splitter. Further mortar-and-pestle crushing, sieving, and riffle splitting provided sample cuts with grain sizes ranging from $<0.125 \mu \mathrm{m} ; 0.5-1.25 \mathrm{~mm} ; 2-4 \mathrm{~mm} ; 5$ $-10 \mathrm{~mm}$; and $10-15 \mathrm{~mm}$ for testing.

\subsection{Acid Leaching Experiments}

Some 150 experiments were performed on various size fractions, with sulfuric ( 1 - 33 vol\%) or hydrochloric (4-12 vol\%) acid, exposure times from 1 to 77 days, with and without agitation (bottle rolls on a shaker table), at room temperature $\left(19^{\circ} \mathrm{C}\right)$, and a few at $70^{\circ} \mathrm{C}$. Sample size was $11 \mathrm{~g}$ for all tests. Solution volume was typically $80 \mathrm{ml}$, with a few tests at 40,20,10, and $5 \mathrm{ml}$. After test completion, samples were rinsed 3 times in deionized water. Pregnant leach solutions (PLS) were centrifuged, passed through a $0.45 \mu \mathrm{m}$ micro-filter, and stored for potential future analysis of such elements as Be and Li that were not accessible by ED-XRF, or for confirmation of XRF results by an independent analytic technique, e.g., ICP-MS.

\subsection{XRF Sample Preparation}

Head and tail (leached) solids were ground in a ball mill to $<10 \mu \mathrm{m}$ nominal diameter and cellulose binder and paraffin sealant were added. A total of $10 \mathrm{~g}$ of material was crushed at 20 tonnes $\mathrm{cm}^{-2}$ pressure into a $25-\mathrm{mm}$-diameter X-ray puck. Samples typically were analyzed in batches on the XRF within several days of their production. The analyzed pucks were then stored in a low humidity environment for subsequent re-analysis by XRF if later required.

\subsection{XRF Analysis}

Samples were analyzed on a PANalytic Epsilon5 ED-XRF with a $25-100 \mathrm{keV}, 0.5$ - 24 $\mathrm{mA}$ side window $\mathrm{X}$-ray tube, with $600 \mathrm{~W}$ maximum power, and a scandium-tungsten dual anode. The unit was equipped with a $30 \mathrm{~mm}^{2} \mathrm{Ge} X$-ray detector with a $140 \mathrm{eV}$ or better resolution (200 cps, Mn K $\alpha$ line). The system permitted excitation and analysis of the high energy K-series emissions of the REEs, rather than the low energy L-series emissions that lie in an energy region with multiple interfering emissions from other elements. The Ge detector provided more efficient capture (due to its greater stopping power) of the high-energy REE K-series characteristic radiation than a typical Si-based detector.

Our PANalytic instrument permitted 8 sequential analysis conditions, based on secondary targets, that optimized excitation of groups of sequential neighboring lower- $Z$ elements. Total analysis time for our application was approximately one hour. Detection limits for the majority of elements between Sc and U across the Periodic Table 
were $1 \mathrm{ppm}$ or less. For the first 3 shown spectra, mostly REEs, the instrument was operated at $100 \mathrm{kV}$ and $6 \mathrm{~mA}$ with an $\mathrm{Al}_{2} \mathrm{O}_{3}$ Barkla scatterer secondary target. For the fourth spectral set, $75 \mathrm{kV}$ at $8 \mathrm{~mA}$ and a Ge secondary target were employed.

\section{Results and Discussion}

\subsection{Spectral Comparisons}

Figure 1 displays the XRF spectra of the head sample (green) and a leached tail (black) in the energy region $24-34 \mathrm{keV}$. Instrument calculated backgrounds, bottom continuous curves, are nearly identical, as expected. Note the near matches of the Sn-Kal (left side of spectrum) and $\mathrm{Sn}-\mathrm{K} \beta 1$ (center of spectrum) emission peaks, indicating that little of the tin, perhaps $5 \%$, was leached by the (in this case) sulfuric acid exposure. If one mentally superimposes the two backgrounds an only slightly larger difference between the two spectra is seen. This low extraction of tin is consistent with the anticipated limited acid solubility of the tin host mineral, cassiterite $\left(\mathrm{SnO}_{2}\right)$, under the experimental leaching conditions [29]. The presence of cassiterite in the Round Top deposit had been determined previously by electron probe microanalysis [27]. To the right side of the graphic, the recovery of Cs into solution is visually seen to have been perhaps $1 / 3$ (tail peak about 2/3 magnitude of head peak), and the recovery of La close to $50 \%$.

It must be emphasized that this approach presents the viewer with the all the actual original data, leaving no questions of how the data were "massaged" through corrections, overlapping peak deconvolutions, standards, calibration curves, etc. into a single sterile number in a table, such as " $52 \%$ recovery for lanthanum". Further, the quality and reliability of the data are evident in the magnitude of the peaks relative to the level of background noise (scale of the vertical zig-zags) in the spectrum, and the presence or absence of overlapping peaks.

If a more robust estimate of the percent recovery of an element is required than that achieved by direct visual comparison of peaks, it is a simple matter to measure and compare the peak heights in the respective spectra on the computer screen or on a print out. Alternatively, peak areas can be calculated via the XRF instrument's computer, with essentially no additional processing of the data. Neither of these approaches, of course, requires any standards; they are simply an extension of the direct peak comparison approach. Comparisons of the visual and measured approaches indicated that the visual estimate was correct within 5\% - 10\%, but became less accurate with the small, jagged peaks generated by elements present at increasingly lower concentrations. The visual comparison is nonetheless adequate for the type of exploratory separation projects of the type we have described.

Figure 2, covering the energy range 33 to $44 \mathrm{keV}$, shows substantial recoveries for the light rare earth elements (LREEs). Despite some peak overlaps, the efficacy of the leach process is obvious.

In Figure 3 we observe nearly complete ("flatline") recoveries of $80 \%-90 \%$ for such target, high value HREEs as $\mathrm{Dy}, \mathrm{Er}, \mathrm{Tb}$, and $\mathrm{Yb}$. The improved recovery of the HREEs compared to the LREEs is evident, consistent with the residence of LREEs in both yt- 


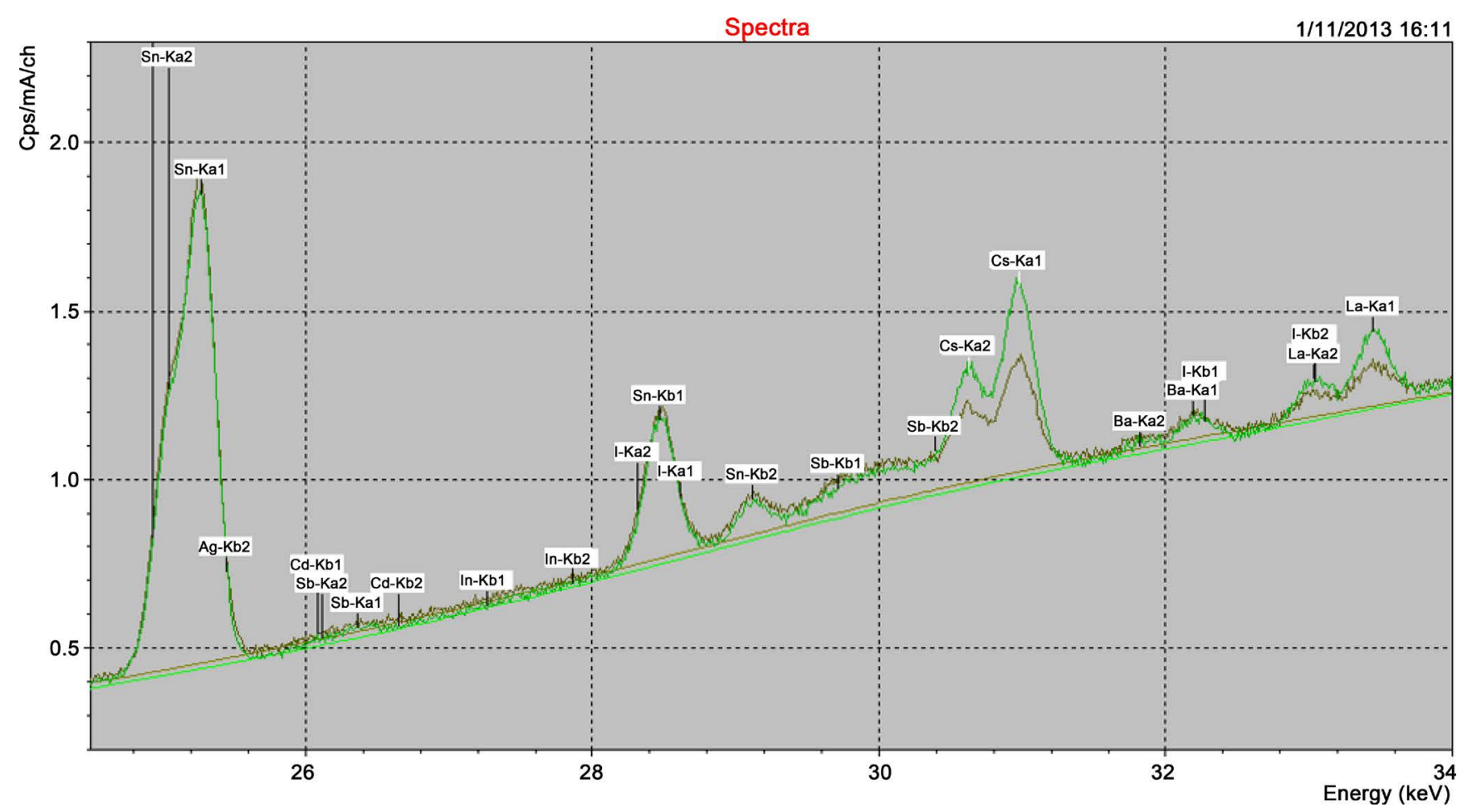

Figure 1. Head (green) and post-leach tail (black) XRF spectra in the energy window from 24 to $34 \mathrm{keV}$ (x-axis). Peak height (y-axis) is recorded X-ray counts per second (Cps) per milliamp (mA) per channel (16,000-channel analyzer). Difference between head and tail curve is portion of target element extracted into leach solution. Note small difference between head and tail for Sn (little extraction), versus significant differences for Cs and La.

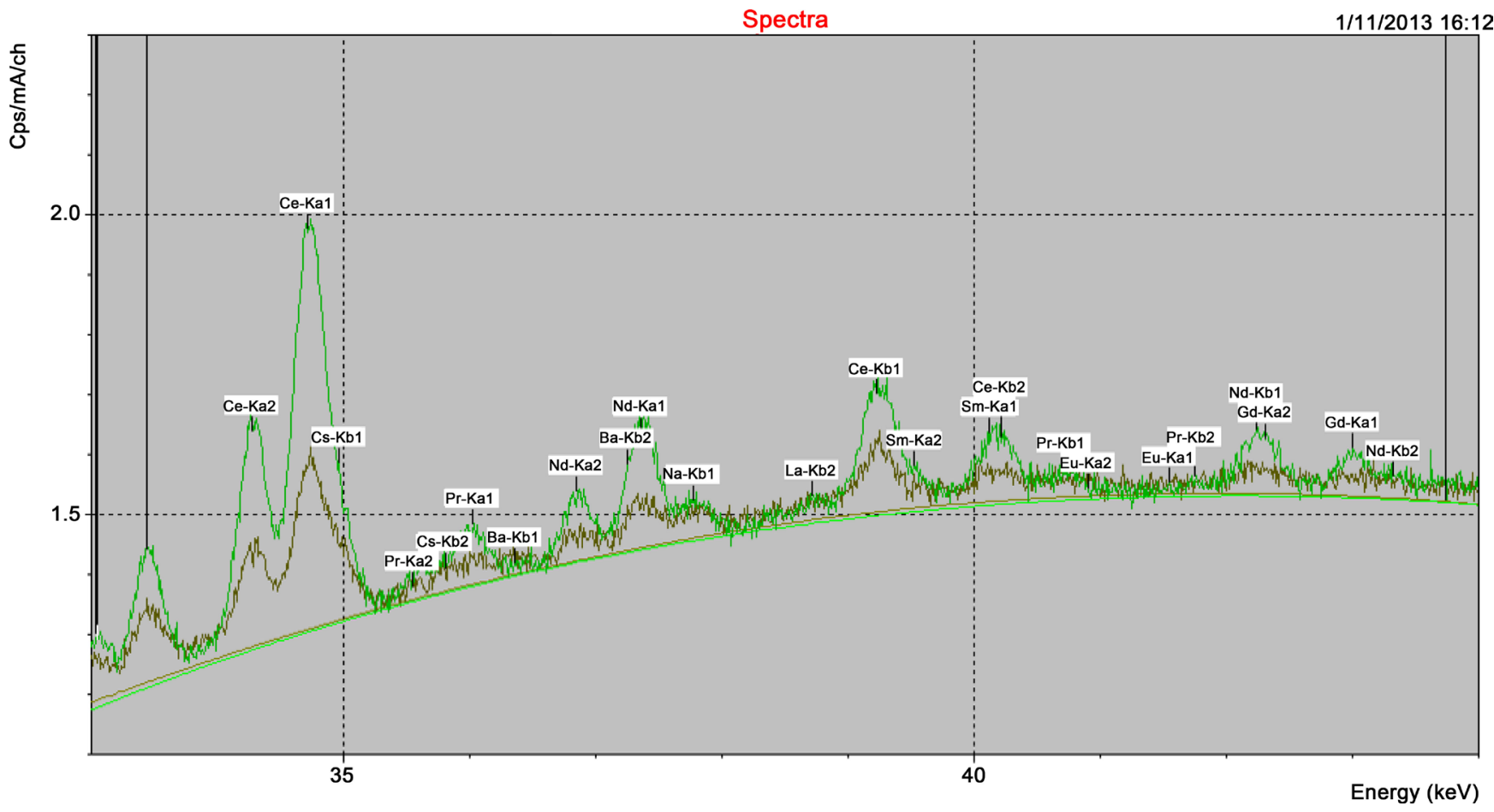

Figure 2. Head and tail spectra in energy range 33 to $44 \mathrm{keV}$. In this sample, significant recoveries are seen for the light REEs. By visual estimate, Ce, at left, has about $55 \%$ recovery, and $\mathrm{Nd}, \mathrm{Sm}$, and $\mathrm{Gd}$ about $65 \%$ recoveries. 


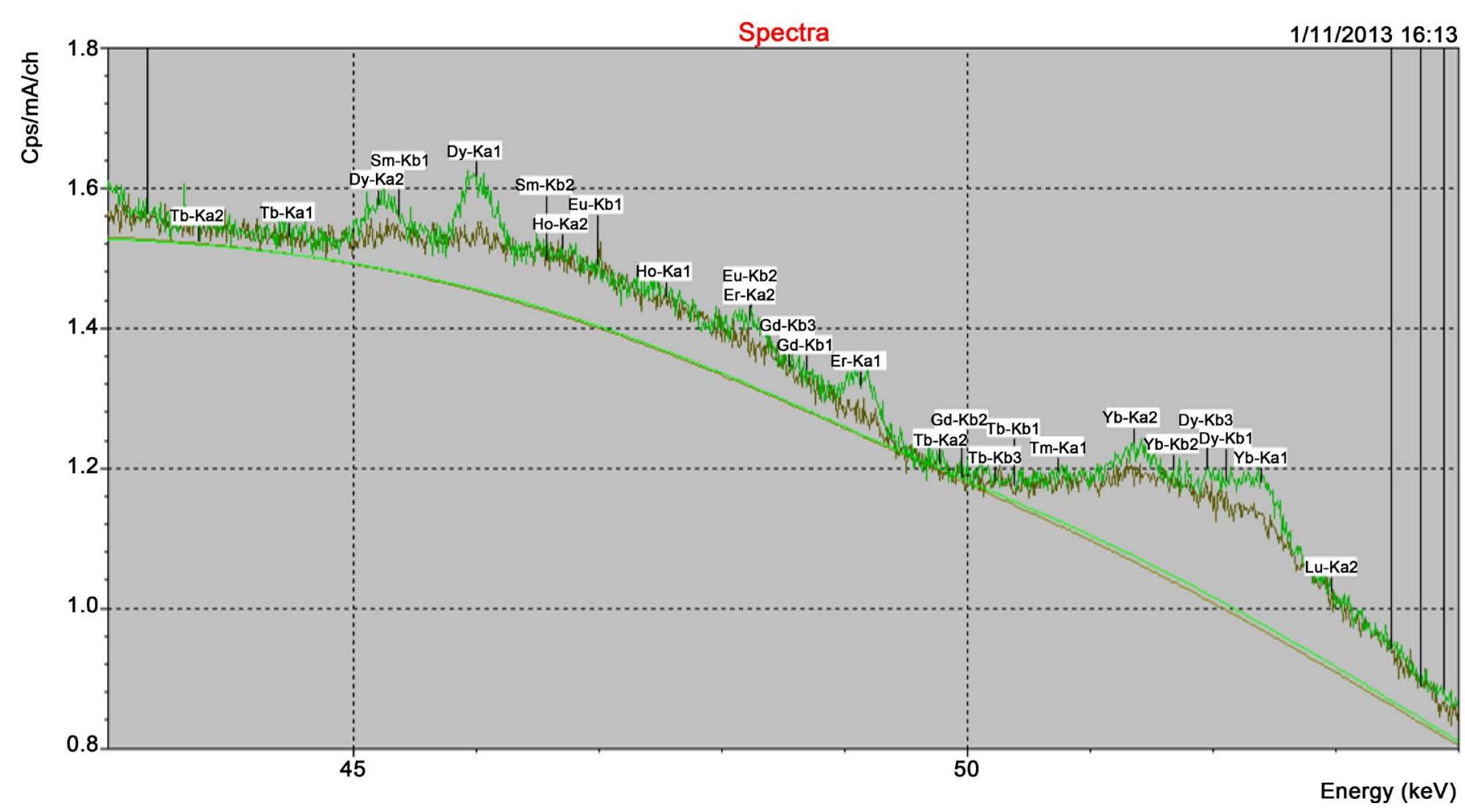

Figure 3. Head and tail spectra in energy range 43 to $54 \mathrm{keV}$. Near complete ("flatline”) recoveries of $80 \%$ - $90 \%$ are evident for such target, high value HREEs as Dy and Yb.

trofluorite and other more chemically resistant minerals [27].

Note the greater signal variation in this high-energy portion of the spectrum evidenced by the increased jaggedness of the curve. Data quality has diminished due to the low concentrations of these elements (Dy in the head material is $30 \mathrm{ppm}$ by independent laboratory determination) and the high $\mathrm{X}$-ray beam energy, $>50 \mathrm{keV}$, required for K-shell excitation of these lanthanides. Nonetheless, data are sufficient to unequivocally document the efficacy of this particular combination of leaching parameters.

The background curves generated by the instrument's computer are a poor fit to the complex background characteristic of this energy portion of all spectra. The algorithm provides a smoothed fit to a wider energy window, failing to distinguish these smaller background features.

Figure 4 presents a separate series of leaches employing 4\% sulfuric acid on the 2 - 4 $\mathrm{mm}$ particle size cut, for exposure times of 1,5 , and 14 days. This low energy spectral window contains several of the so-called rock-forming elements of the rhyolite, including $\mathrm{Al}, \mathrm{Si}$, and $\mathrm{K}$, as well as secondary and minor elements $\mathrm{Fe}, \mathrm{Zn}$, and $\mathrm{Mn}$. The peaks for the major elements at left display far greater magnitudes under different analytical conditions employing lower-Z secondary targets, not presented here. The orderly increase in extraction of these gangue elements with increasing leach times is evident. The target YHREEs would have to be separated from the Fe, Zn, and Mn in the PLS by a subsequent process; from an economic standpoint for the recovery of REEs, the less gangue in the PLS, the better. 


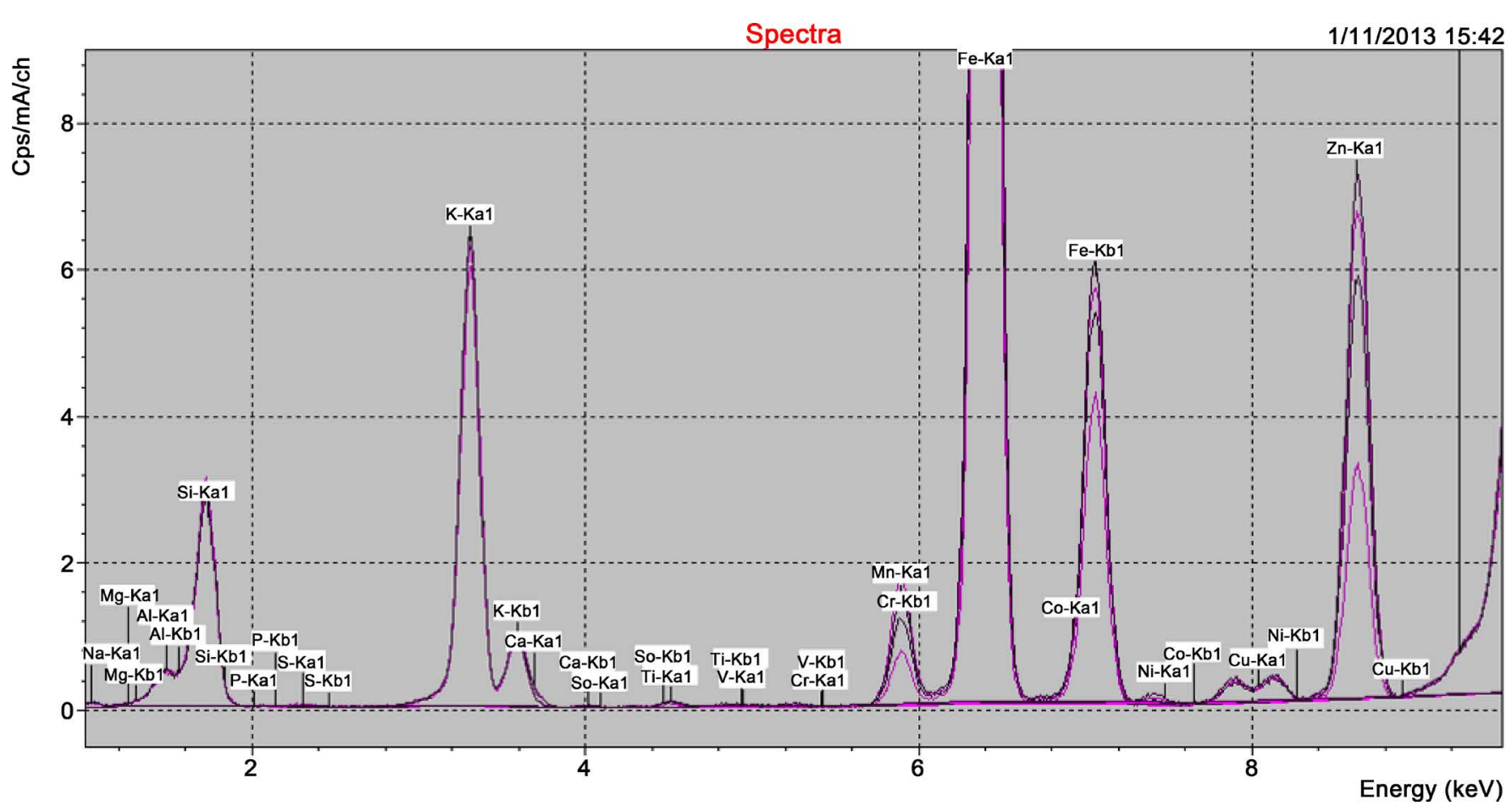

Figure 4. Head and tail spectra in energy range 1 to $9.5 \mathrm{keV}$. Here spectra of leached tails from three different exposure times using $4 \%$ sulfuric acid on 2 - $4 \mathrm{~mm}$ particles are compared to the head sample, the upper black curve. Upper red curve is 1 day, lower black curve 5 days, and lower red curve 2 weeks. Increasing dissolution of such undesirable gangue metals as $\mathrm{Mn}$, Fe, and $\mathrm{Zn}$ with increased leach time is evident.

For the full set of experiments, calculated target HREE recoveries ranged from 20\% to $90 \%$. Higher acid strength, finer grain size, and longer exposure times produced greater HREE extraction, as well as greater extraction of other byproduct and gangue elements.

\subsection{Discussion}

There are two keys to the validity of the standardless comparison approach. First, the close compositional similarities of head and tail samples ensures, in effect, "matrix matching", eliminating the need for such procedures as Fundamental Parameters to correct for such effects as differential X-ray absorption in the sample. Second, the identical sample puck preparation and analytical protocols performed on each requires no adjustment for different analysis conditions.

We next highlight the advantages and disadvantages of the technique, and more closely define the types of projects where it is most valuable. Because the technique does not require standards, it is an ideal protocol to quickly start the analytical part of an experimental leaching or other beneficiation project. Assembly or acquisition of standards, even multi-element ones, for more than 75 elements, fabrication of pucks, XRF runs, validation and checking of calibration curves, and other tasks would be expected to take at least several weeks of full time effort-assuming that no problems arise. The comparative approach can generate the required data literally within a few hours after 
fabrication of head and tail pucks. Thus time-sensitive data on extraction efficiency can be provided to the leaching project personnel to guide their next set of experiments. Should full quantification for the project be required, the calibration process can be attended to while providing the standardless analysis for immediate project guidance. Typically in the early stages of leaching experiments large and easily discernable differences in extraction efficiency are expected as a wide range of experimental parameters is explored. Formal quantification might be important only in the late stages of leaching refinement.

An important feature of this comparative approach is the preservation of the original data in the spectral presentation. A few minor adjustments are made in the XRF computer (e.g., fluctuation in beam output, background fitting), but there is no further significant data processing. This eliminates any audience concerns or questions about what took place in the processing "black box". Data quality is obvious from the observable signal-to-noise ratio: peak magnitude versus vertical spectrum zig-zagging is fully revealing. Processed, tabular results often include such corrections as deconvolution of overlapping peaks, but that fact would not be noted downstream in a presentation table or histogram. In contrast, the overlapping peaks would be obvious in the visual comparison approach.

It should be realized that application of this protocol is not limited to leaching procedures. It can be applied as well to any of the other traditional ore processing and beneficiation procedures. These include, for example, gravity concentration, magnetic and electrical separation, froth flotation, and ore sorting.

There are prerequisites to using this plan. First, careful riffle splitting of the particles to be leached is required to ensure that one or a few (to test consistency) head grade analyses represent material identical to that tested in the leach experiments. Second, post-leach sample preparation protocols and XRF instrument analysis settings must be followed exactingly to ensure valid comparison conditions. Third, the leaching process should not dissolve more than perhaps $10 \%$ of the bulk rock. The greater the dissolution, the greater the likelihood that the matrix match condition could be compromised by the loss of specific components. In practice, leach conditions that extensively dissolve the gangue would be eliminated from consideration due to the excess consumption of acid or other leaching solution and the need for additional subsequent purification of the leach solution. Fourth, it is advantageous, but not essential, that the concentration of target elements in the head sample be previously established. This permits an estimation of quantitative process recoveries. Typically such information is available from the large compositional data sets acquired during the exploration phase of a mining project.

\section{Conclusions}

The standardless comparison approach is simple and rapid, and is shown to be valid when proper application protocols are respected. It retains and presents all features of the original data, thus eliminating questions about data quality and how the data were 
manipulated in processing from raw counts to concentrations.

This technique eliminates the time and expense associated with generating calibration curves for multiple elements. Acquisition of standards for perhaps 50 - 75 elements and at multiple concentrations of each, preparation of sample pucks, XRF instrumental analysis, and generation and vetting of calibration curves represent a serious financial and temporal burden, often during a critical period in the development stage of a mining operation. These preparatory steps might even entail more effort than the analyses of actual samples in a modest exploratory extraction program. The standardless approach provides essentially all the information that is needed about the progression of the separation processes being evaluated and refined. If full quantitative analyses are required at a later time, the standardless analysis data can simply be entered into the XRF computer program after calibration of the instrument with appropriate standards.

Direct visual comparison of superimposed head and post-leach XRF spectral peaks provides a dramatic graphical representation of the efficacy of the leaching process. It is particularly valuable for display to both the working professional and to such less technically savvy individuals and groups as corporate decision makers and staff, investors, regulators, and the public. The retention of all features of the original data in this manner of presentation brings confidence and integrity to the communication of experimental results.

\section{Acknowledgements}

The authors thank Texas Mineral Resources Corp. for access to samples and technical data. This project was supported by joint research contracts 26-8211-12 and 26-8211-16 between TMRC and the University of Texas at El Paso. Funds to cover the costs to publish in open access were obtained from this source.

\section{Disclosure}

NEP serves on the Board of Directors of TMRC. He is not and has never been an employee of TMRC, nor has he received any compensation from the research contracts that supported this research. DG is the CEO of TRER and serves on its Board of Directors.

\section{References}

[1] Wills, B.A. and Finch, J. (2015) Mineral Processing Technology. 8th Edition, Elsevier, Amsterdam.

[2] Habashi, F. (2003) Metals from Ores. An Introduction to Extractive Metallurgy. Métallurgie Extractive Québec, Québec.

[3] Rosenqvist, T. (2004) Principles of Extractive Metallurgy. 2nd Edition, Tapir Academic Press, Trondheim.

[4] Metso Mining and Construction (2015) Basics in Mineral Processing. 354 p. http://www.metso.com/miningandconstruction/MaTobox7.nsf/DocsByID/EAE6CA3B8E21 6295C2257E4B003FBBA6/\$File/Basics-in-minerals-processing.pdf

[5] Gupta, A. and Yan, D. (2016) Mineral Processing Design and Operation. 2nd Edition, El- 
sevier, Amsterdam.

[6] Rao, G.S.R. (2015) Mineral Processing Techniques. Zorba Publishers, Gurgaon (India).

[7] Wills, B.A. and Barley, R.W. (2012) Mineral Processing at a Crossroads: Problems and Prospects. Springer, Rotterdam.

[8] Zanbak, C. (2012) Heap Leaching Technique in Mining within the Context of Best Available Techniques (BAT). The European Association of Mining Industries, Metal Ores \& Industrial Minerals, $33 \mathrm{p}$.

http://www.euromines.org/files/mining-europe/mining-techniques/batforheapleaching-feb 2013-c.zanbak-euromines.pdf

[9] Bartlett, R.W. (1997) Metal Extraction from Ores by Heap Leaching. Metallurgical and Materials Transactions B, 28b, 529-545. http://dx.doi.org/10.1007/s11663-997-0026-2

[10] Dhawan, J., Safarzadeh, M.S., Miller, J.D., Rajamani, R.K. and Moats, M.S. (2012) Insights into Heap Leach Technology. Proceedings of the 2012 SME Annual Meeting and Exhibit, Washington, 19-22 February 2012, 560-567.

[11] Ghorbani, Y., Franzidis, J.-P. and Petersen, J. (2015) Heap Leaching Technology-Current State, Innovations and Future Directions: A Review. Mineral Processing and Extractive Metallurgy Review. http://dx.doi.org/10.1080/08827508.2015.1115990

[12] Caceres, O. (2013) Lessons Learned in Heap Leaching Technology Implementation. The First International Heap Leach Solutions Conference, 22-25 September 2013, VancouverCanada.

http://mining.solutions/heapleach/2013/wp-content/uploads/2013/10/Omar-Caceres-HeapLeaching-technology-Implementation-Lessons-learned.pdf

[13] Scheffel, R. (2010) Heap Leaching Design for Success-A Case Study. Low-Grade Uranium Dump and Heap Leach Technical Meeting, 29-31 March 2010, International Atomic Energy Agency (IAEA), Nuclear Fuel Cycle and Materials Section, Vienna International Center, WagramerStrasse, Vienna, Austria. https://www.iaea.org/OurWork/ST/NE/NEFW/documents/RawMaterials/TM LGUO/5f\%2 0Scheffel\%20Heap\%20Leach\%20Design.pdf

[14] Burnett, B.J., Lawrence, N.J., Abourahma, J.N. and Walker, E.B. (2016) Rapid Analysis of Copper Ore in Pre-Smelter Head Flow Slurry by Portable X-Ray Fluorescence. Applied Spectroscopy, 1-3. http://dx.doi.org/10.1177/0003702816638282

[15] Quinou, T. and Laperche, V. (2014) An Assessment of Field-Portable X-Ray Fluorescence Analysis for Nickel and Iron in Laterite Ore (New Caledonia). Geochemistry Exploration Environment Analysis, 14, 245-255. http://dx.doi.org/10.1144/geochem2012-159

[16] Niemela, A., Hasikova, E. and Titov, V. (2015) Real-Time Material Flow Analysis on Conveyor Belts. IFAC-PapersOnLine, 48, 24-27. http://dx.doi.org/10.1016/j.ifacol.2015.10.071

[17] Hasikova, J., Sokolov, A., Titov, V. and Dirba, A. (2014) On-Line XRF Analysis of Phosphate Materials at Various Stages of Processing. Procedia Engineering, 83, 455-461. http://dx.doi.org/10.1016/j.proeng.2014.09.078

[18] Sjöqvist, A.S.L., Arthursson, M., Lundström, A., Calderón Estrada, E., Inerfeldt, A. and Lorenz, H. (2015) An Innovative Optical and Chemical Drill Core Scanner. Scientific Drilling, 19, 13-16. http://dx.doi.org/10.5194/sd-19-13-2015

[19] Cnudde, V. and Boone, M.N. (2013) High-Resolution X-Ray Computed Tomography in Geosciences: A Review of the Current Technology and Applications. Earth-Science Reviews, 123, 1-17. http://dx.doi.org/10.1016/j.earscirev.2013.04.003

[20] Dhawan, N., Safarzadeh, S., Miller, J.D., Moats, M.S., Rajamani, R.K. and Lin, C.L. (2012) Recent Advances in the Application of X-Ray Computed Tomography in the Analysis of 
Heap Leaching Systems. Minerals Engineering, 35, 75-86.

http://dx.doi.org/10.1016/j.mineng.2012.03.033

[21] Lina, Q., Neethling, S.J., Courtois, L., Dobson, K.J. and Lee, P.D. (2016) Multi-Scale Quantification of Leaching Performance Using X-Ray Tomography. Hydrometallurgy, 164, 265 277. http://dx.doi.org/10.1016/j.hydromet.2016.06.020

[22] Henry, C.D., McDowell, F.W., Price, J.G. and Smyth, R.C. (1986) Compilation of Potassium-Argon Ages of Tertiary Igneous Rocks, Trans-Pecos, Texas. University of Texas, Bureau of Economic Geology, Austin, 1-34.

[23] Rubin, J.N., Price, J.G., Henry, C.D. and Koppenaal, D.W. (1987) Cryolite-Bearing and Rare Metal-Enriched Rhyolite, Sierra Blanca Peaks, Hudspeth County, Texas. American Mineralogist, 72, 1122-1130.

[24] Price, J.G., Rubin, J.N., Henry, C.D., Pinkston, T.L., Tweedy, S.W. and Koppenaal, D.W. (1990) Rare-Metal Enriched Peraluminous Rhyolites in a Continental Arc, Sierra Blanca Area, Trans-Pecos Texas. Chemical Modification by Vapor-Phase Crystallization. GSA Special Papers, 246, 103-120. http://dx.doi.org/10.1130/SPE246-p103

[25] Gustavson Associates (2012) NI 43-101 Preliminary Economic Assessment. Round Top Project, Sierra Blanca, Texas. http://trer.com/wp-content/uploads/2012/06/TRER NI\%2043-101\%20PEA KLG 037.pdf

[26] Pingitore Jr., N., Clague, J. and Gorski, D. (2012) Round Top Mountain Rhyolite (Texas, USA), A Massive, Unique Y-Bearing-Fluorite-Hosted Heavy Rare Earth Element (HREE) Deposit. The Journal of Rare Earths, 32, 90-96. http://dx.doi.org/10.1016/S1002-0721(14)60037-5

[27] O’Neill, L.C. (2014) REE-Be-U-F Mineralization of the Round Top Laccolith, Sierra Blanca Peaks, Trans-Pecos, Texas. Master's Thesis, University of Texas, Austin.

[28] Yttrofluorite. Mindat.org. http://www.mindat.org/gallery.php?min=4371

[29] Crawford, J. (2009) Solubility Data on 646 Common and Not So Common Minerals. http://www.mindat.org/article.php/553/Solubility+Data+on+646+Common+and+Not+So+ $\underline{\text { Common }+ \text { Minerals }}$

Submit or recommend next manuscript to SCIRP and we will provide best service for you:

Accepting pre-submission inquiries through Email, Facebook, LinkedIn, Twitter, etc.

A wide selection of journals (inclusive of 9 subjects, more than 200 journals)

Providing 24-hour high-quality service

User-friendly online submission system

Fair and swift peer-review system

Efficient typesetting and proofreading procedure

Display of the result of downloads and visits, as well as the number of cited articles

Maximum dissemination of your research work

Submit your manuscript at: http://papersubmission.scirp.org/

Or contactajac@scirp.org 